\title{
A IGREJA E O ESCÂNDALO DA PEDOFILIA
}

\section{The Church and the pedophilia scandal}

\author{
Luís Corrêa Lima SJ *
}

RESUMO: O escândalo da pedofilia envolvendo o clero católico teve uma enorme repercussão na mídia. Para além de fatos pontuais amplamente noticiados, há uma realidade social da Igreja, do clero e da sociedade contemporânea que se manifesta, onde os agentes estão interligados e interagindo, e podem ser melhor conhecidos. Avaliam-se a dimensão do escândalo, desdobramentos e consequências, polêmicas que se seguiram, e a pertinência de medidas adotadas.

PalaVRas-Chave: Clero, Pedofilia, Homossexualidade, Papa Bento XVI.

ABSTRACT: The pedophilia scandal involving the Catholic clergy had a huge impact in the media. Beyond specific events widely reported, there is a social reality of the Church, the clergy and of contemporary society which is manifested, where the agents are interconnected and interacting, and may be better known. The extent of the scandal, developments and consequences, controversy that followed, and adequacy of measures taken are evaluated.

KEYwords: Clergy, Pedophilia, Homosexuality, Pope Benedict XVI.

\footnotetext{
* Departamento de Teologia da PUC (Rio de Janeiro). Artigo submetido a avaliação no dia 21/02/2011 e aprovado para publicação no dia 22/02/2011.
} 
Crande perplexidade e mal-estar afligiram a Igreja Católica em todo o J mundo quando foram divulgados casos de pedofilia cometida por membros do clero. Os períodos de mais denúncia foram o ano de 2002, com o foco nos Estados Unidos, e o final de 2009 e primeiro semestre de 2010, com o foco no Centro e no Norte da Europa.

A crise nos Estados Unidos já vinha desde os anos 90, mas culminou com a renúncia do cardeal-arcebispo de Boston, Bernard Law, e com a visita dos bispos norte-americanos ao papa, a fim de tratarem especificamente deste assunto. A crise na Europa eclodiu na Irlanda em 2009, com a divulgação de relatórios do governo irlandês, com a conclusão de longas investigações sobre abusos sexuais em internatos católicos. Novas denúncias pulularam em outros países, impulsionadas pela internet que permite às vítimas se comunicarem e se apoiarem mutuamente.

Esta última onda coincidiu com o Ano Sacerdotal, período convocado pelo papa para santificação do clero, mediante oração, celebração e reflexão. Algumas autoridades eclesiásticas tentaram minimizar a crise acusando a imprensa de fofoca, mas só geraram mais protestos indignados.

A crise nos Estados Unidos resultou na condenação de cerca de mil e oitocentos sacerdotes pelos tribunais, por casos de abusos cometidos entre 1950 e 2000. Atribui-se esta crise a diversos fatores como um anticatolicismo, que naquele país supera o antissemitismo, aos interesses do governo Bush (contrários às posições da Igreja Católica no plano político internacional), ao anticlericalismo do jornal New York Times e à indústria das indenizações judiciais, com um enorme contingente de advogados ávidos de encontrarem vítimas. Estes fatores podem ter agravado a situação, mas a razão principal é que as autoridades da Igreja não comunicaram os casos de abuso ao poder civil, preferindo o acordo com as vítimas e seus familiares, e a remoção dos padres acusados mediante arrependimento e encaminhamento para tratamento psicológico.

Este modo de proceder era uma maneira de resolver a questão internamente, preservando o bom nome da Igreja. Também concorreu para isto um parecer de psicólogos que foi apresentado aos bispos norte-americanos em 1992. Acreditava-se que a pedofilia pudesse ter cura, e que se deveria dar chance aos sacerdotes envolvidos. Apontam-se como agravantes da crise muitas nomeações de bispos feitas por João Paulo II, em que pessoas com mais abertura, liderança e capacidade pastoral foram preteridas em favor de outras menos expressivas e capazes, mas obedientes.

Alguns casos de pedofilia tiveram repercussão maior, como o do cardealarcebispo de Viena, Hans Hermann Groer, acusado de ter abusado de adolescentes seminaristas quando era professor no seminário; e o do fundador dos Legionários de Cristo, o padre mexicano Marcial Maciel Degolado. Este último foi publicamente denunciado por vários ex-alunos de se- 
minário ${ }^{1}$, e não obstante era recebido em audiência e efusivamente elogiado pelo papa João Paulo $\mathrm{II}^{2}$ e pelo cardeal Ângelo Sodano, então secretário de Estado do Vaticano. Só depois que Ratzinger se tornou papa é que Maciel foi punido, com a proibição de celebrar publicamente qualquer sacramento.

Uma leitura capaz de explicar estes acontecimentos não é simples. Há quem veja aí uma "onda sexista" que domina o mundo, sobretudo o Ocidente, acirrando os instintos. É uma exasperação sexual com a consequente busca do prazer a qualquer preço. Ela é responsável pela lucrativa indústria do prazer exótico, que procura justamente as crianças. $\mathrm{O}$ turismo sexual, praticado em larga escala em diversos países, sempre abrange crianças e adolescentes. Esta indústria tem um braço poderoso em "sites" da internet. Nesta linha de explicação, a maldade humana deve ser compreendida na conjugação do pecado pessoal, do social e do original. Deve-se a transcender a patologia individual e abarcar o social ${ }^{3}$.

Esta suposta conexão entre a "onda sexista" e a pedofilia clerical, porém, não é clara. Muitos casos são anteriores ao final dos anos 60, época da irrupção da revolução sexual. E há casos que não têm relação com o turismo sexual ou com a internet. Convém observar que o clero não é mais pedófilo do que outros segmentos da sociedade, mas a pedofilia praticada por clérigos tem uma repercussão muito maior, sobretudo na mídia. Aí está o principal foco da questão, que precisa ser analisado.

No bojo da revolução sexual, há uma desinibição para se tratar publicamente de questões sexuais, sem poupar em nada qualquer autoridade civil ou eclesiástica. Nos anos 90, o presidente norte-americano Bill Clinton sofreu um verdadeiro massacre da mídia por seu envolvimento com a estagiária Mônica Lewinsky. Ele chegou a sofrer um processo de impeachment, mas foi absolvido pelo Senado. A bem da verdade, a acusação não era de sexo, mas de perjúrio: ele teria mentido em depoimento sob juramento, negando o envolvimento. No auge do processo, ele foi submetido a um interrogatório de quatro horas, transmitido ao vivo pela televisão em todo o mundo. Nenhum cardeal ou bispo católico viveu um constrangimento semelhante.

Tanto nos Estados Unidos quanto em outros países, a recusa das autoridades da Igreja em comunicar os casos de abuso ao poder civil é, sem dúvida, uma das principais causas da crise. Esta recusa era corroborada pela Santa Sé. O cardeal Darío Castrillón, prefeito da Congregação para o Clero no

\footnotetext{
${ }^{1}$ PEPE RODRIGUEZ, "Carta abierta enviada al papa Juan Pablo II, en noviembre de 1997, por ocho ex miembros de los Legionarios de Cristo que acusan a su fundador, Marcial Maciel, de haber abusado sexualmente de ellos cuando eran adolescentes". Disponível em: www.pepe-rodriguez.com. Acesso em: 17 fev. 2011.

2 "Discurso do Papa João Paulo II aos Legionários de Cristo e aos Membros do Movimento 'Regnum Christi' ”, 30 nov. 2004. Disponível em: <www.vatican.va>. Acesso em: 17 fev. 2011.

${ }^{3}$ A. MOSER, "Pedofilia: reflexões a partir de escândalos recentes", Revista Eclesiástica Brasileira (2010/n.278) 423-435.
} 
tempo de João Paulo II, chegou a escrever a um bispo da França felicitandoo por não ter denunciado um padre de sua diocese à administração civil: é um "modelo de pai que não entrega os seus filhos"4. Pode-se ver aí um resíduo da cristandade, dos tempos do Estado confessional cristão. Resolvia-se o problema no âmbito interno da Igreja, que deve proceder como uma família. No máximo se recorria ao tribunal eclesiástico para julgar crimes cometidos por clérigos. Contudo, a questão não ultrapassava a fronteira eclesial. Este procedimento que perdurou até o final do século 20 é, no fundo, uma recusa à modernidade, à lei impessoal e igual para todos.

Outra causa é a exaltação da figura do sacerdote na Igreja Católica. Desde o Concílio de Trento no século 16, surgiu uma mística em torno de sua pessoa. A criação dos seminários separou do meio social de origem os que se destinavam ao sacerdócio ministerial. Da pré-adolescência em diante, o futuro padre tinha moradia, formação, hábitos e vestes próprios, distintos dos outros homens. Era visto como um ser angelical, algo extramundano. O padre assume uma aura de distância, de santidade, de misticismo, que lhe dá uma autoridade e uma força inculcadora únicas. A Igreja acentuou de tal maneira a figura do clérigo, identificou-se de tal modo com ele, que os opositores da Igreja eram designados não como anti-eclesiásticos, mas como anticlericais.

O Ano Sacerdotal trouxe ecos desta exaltação. Uma frase de São João Maria Vianney, padroeiro dos sacerdotes, foi lema de algumas comemorações: “Depois de Deus, o sacerdote é tudo". Esta exaltação tem seu preço. Uma falta grave como a pedofilia, cometida por um sacerdote, torna-se muito mais grave, um mal incomensurável. E as repercussões inevitavelmente são maiores.

Uma terceira causa é o peso do discurso moral da Igreja no campo sexual, como bem constatou o ex-superior geral dos dominicanos, Timothy Radcliffe. Pregando retiro ao clero de Dublin (Irlanda), ele constatou:

Dissemos às famílias com um grande número de crianças que não era permitido nenhum tipo de contracepção, aos jovens, que não têm a possibilidade de se casarem e que devem controlar a sua atividade sexual de maneira muito severa - não mais de dez segundos por beijo - e aos homossexuais, que nada é permitido e que devem ter vergonha da sua sexualidade. Ora, independentemente dos anexos e conexões dos ensinamentos da Igreja, estas recomendações foram vividas pelos nossos fiéis como um fardo pesado. E os fiéis depois descobrem que os padres que lhes impunham as obrigações pecaram no âmbito sexual de maneira muito mais grave. Como os fariseus, não fazendo aquilo que diziam ${ }^{5}$.

\footnotetext{
4 "Bispo foi elogiado por proteger pedófilo", O Estado de São Paulo, 17 abr. 2010. Disponível em: <http://www.estadao.com.br/estadaodehoje/20100417/ not_imp539515,0.php>. Acesso em: 26 out. 2010.

5 "A crise da Igreja pode ser saudável", Boletim eletrônico IHU, 17 abr. 2010. Disponível em: <www.ihu.unisinos.br>. Acesso em: 25 jan. 2010.
} 
Este fardo pesado torna os fiéis e a sociedade muito sensíveis aos deslizes do clero. No caso do cardeal Groer, por exemplo, a denúncia à imprensa foi feita por um homem adulto que na adolescência tinha sido seminarista, e fora abusado sexualmente pelo prelado no tempo em que ele era formador no seminário. A razão da denúncia foi a indignação da vítima com um duro discurso que o cardeal tinha feito contra os homossexuais.

O enfrentamento dos escândalos levou a Igreja nestes últimos anos a tomar medidas importantes. Os procedimentos em caso de denúncia foram unificados e preveem o encaminhamento à Congregação para Doutrina da Fé. A lei civil referente à denúncia de crime à autoridade competente, sempre deve ser seguida. Durante a fase preliminar e até que o caso esteja concluído, o bispo local pode impor medidas preventivas para proteger a comunidade e as vítimas, restringindo as atividades de qualquer padre em sua diocese ${ }^{6}$.

O papa Bento XVI, além de punir o fundador dos Legionários de Cristo e de intervir nesta instituição, reconheceu as falhas da hierarquia católica por não ter agido com a devida energia. Em diversas ocasiões, encontrou-se com as vítimas e pediu perdão a Deus e a elas pelas faltas cometidas. Diversos pronunciamentos do papa e uma carta pastoral aos católicos da Irlanda ${ }^{7}$, marcam uma postura assertiva de quem enfrenta o problema para valer. Alguns bispos chegaram a pedir renúncia por reconhecerem a própria omissão.

No Brasil a crise repercutiu principalmente por causa do noticiário externo. Porém, as denúncias de pedofilia cometida na última década no País por sacerdotes não passam de trinta. De qualquer maneira, a CNBB se pronunciou sobre o assunto. Os bispos reconhecem o mal irreparável feito às vítimas e suas famílias e lhes oferecem apoio. Quanto ao tratamento do delito, devem-se levar em consideração três atitudes: para o pecador, a conversão, a misericórdia e o perdão; para a transgressão, a aplicação das penalidades eclesiásticas e civis; para a patologia, o tratamento8.

Diversas medidas foram tomadas pelos bispos, entre as quais a publicação de orientações para uma acurada seleção de candidatos ao seminário. Desejase a admissão de pessoas com indispensável saúde física e mental, com equilíbrio moral, psicológico e espiritual. Também se recomendam as instru-

\footnotetext{
6 "Guia para entender os procedimentos básicos do Vaticano com relação à pedofilia", Boletim eletrônico IHU, 13 abr. 2010. Disponível em: <www.ihu.unisinos.br>. Acesso em: 25 jan. 2010.

7 "Carta pastoral do santo padre Bento XVI aos católicos na Irlanda", 19 mar. 2010. Disponível em: <www.vatican.va>. Acesso em: 17 fev. 2011.

8 "Pronunciamento da Presidência da CNBB sobre os abusos sexuais na Igreja", Boletim eletrônico IHU, 14 mai. 2010. Disponível em: <www.ihu.unisinos.br>. Acesso em: 25 jan. 2010.
} 
ções de um documento romano sobre o discernimento vocacional de candidatos ao sacerdócio com tendências homossexuais?.

Este é um ponto bastante complexo e conflitivo: a associação entre pedofilia e homossexualidade. Em 2010, o secretário de Estado do Vaticano negou, em uma entrevista, qualquer relação entre celibato sacerdotal e pedofilia. Mas afirmou que, segundo psicólogos e psiquiatras, existe uma relação entre homossexualidade e pedofilia. Isto causou forte indignação e protestos.

Uma associação internacional de homossexuais lançou uma campanha com um cartaz contendo duas imagens. Em uma delas, um padre com um clergyman escuro e a frase: "A pedofilia é crime, a homossexualidade não". Na outra imagem, um bispo com batina vermelha, uma cruz peitoral e a frase: "Encobrir um delito também é delito"10. Alguns articulistas, por sua vez, fizeram duras críticas ao celibato sacerdotal, considerando-o negação alucinada da sexualidade ${ }^{11}$ e coisa de dar medo ${ }^{12}$.

No Vaticano, o diretor da Sala de Imprensa, Frederico Lombardi, emitiu uma nota de esclarecimento: as autoridades da Igreja não consideram de sua competência fazer afirmações gerais de caráter especificamente psicológico ou médico, para os quais se deve remeter aos estudos dos especialistas. O que é de competência da autoridade eclesiástica são os dados estatísticos dos casos de abuso sexual tratados pela Congregação para a Doutrina da Fé. Segundo estes dados, $10 \%$ dos casos são de pedofilia em sentido estrito, onde as vítimas são crianças. Os outros casos, $90 \%$, são de efebofilia, onde as vítimas são adolescentes. Destes, dois terços são masculinos; e um terço, feminino. As estatísticas se referem ao conjunto destes casos, e não à população em geral ${ }^{13}$.

Na verdade, a pedofilia é causada por uma fantasia perversa de se aproveitar da inocência de uma criança. A maioria dos casos ocorre dentro de casa, e o responsável é o pai ou padrasto dela. Este abuso pode ser cometido por adultos héteros ou homossexuais, ativos sexualmente ou celibatários. Não é questão de orientação sexual, nem de prática ou abstinência sexual. Um

${ }^{9}$ CONGREGAÇÃO PARA A EDUCAÇÃO CATÓLICA, "Instrução sobre os critérios de discernimento vocacional acerca das pessoas com tendências homossexuais e da sua admissão ao seminário e às ordens sacras", Roma, 2005. Disponível em: <www.vatican.va>. Acesso em: 25 jan. 2011.

10 "Nuevas acusaciones de abusos sexuales empañan la visita del Papa al Reino Unido", Cristianos Gays, 21 ago. 2010. Disponível em: <www.cristianosgays.com>. Acesso em: 25 jan. 2011.

11 A. JABOR, "Só os anjos não têm sexo", O Estado de São Paulo, 20 abr. 2010. Disponível em: <www.estadao.com.br>. Acesso em: 25 jan. 2011.

${ }^{12}$ B. GANCIA, "É o celibato, estúpido!", Blog Cella, 16 abr. 2010. Disponível em: <http:/ /www.cella.com.br/blog/?p=18862>. Acesso em: 25 jan. 2011.

13 "Dichiarazione del Direttore della Sala Stampa della Santa Sede, P. Federico Lombardi, SJ, 14.04.2010", Chiesa Cattolica. Disponível em: <www.chiesa-cattolica.com>. Acesso em: 25 jan. 2011. 
pedófilo poderá eventualmente desejar uma mulher e casar com ela. Mas o fato de cumprir o dever conjugal, mesmo com afinco, não o livra de fantasias pedofílicas ${ }^{14}$.

Mesmo quando as vítimas são predominante ou exclusivamente masculinas, isto não caracteriza o agressor como homossexual. No caso de Marcial Maciel, por exemplo, contam-se mais de duzentas vítimas ${ }^{15}$. Sabe-se também que ele foi amante de mulheres adultas, e que teve filhos com elas. Mas não consta que Maciel foi amante de homens adultos. Não se pode dizer que ele era um homossexual.

O papa Bento XVI foi aos Estados Unidos em 2008, e tratou várias vezes da pedofilia cometida pelo clero. Certa vez, entrevistado por um jornalista sobre o assunto, ele ponderou: "não vou falar neste momento de homossexualidade, é outra coisa"16. Distinguir as coisas, como fez o papa, afasta uma injusta suspeita de perversidade que às vezes paira sobre os gays.

Por tudo isso, a entrevista do secretário de Estado do Vaticano não deve ser tomada como posição oficial da Igreja, pois isto coloca indevidamente a Igreja contra os gays, e vice-versa. E nem se deve defender os gays apedrejando o celibato sacerdotal. Ordenar pessoas casadas é prática da Igreja Católica nos ritos orientais, bem como dos cristãos ortodoxos. Há quem defenda esta prática também no Ocidente, para se ampliar o acesso ao sacerdócio e aumentar o número de candidatos. Mas não se deve de modo algum acabar com o celibato por causa dos escândalos de pedofilia, nem repudiar suas motivações espirituais autênticas e legítimas, como se se tratasse de uma negação alucinada da sexualidade.

Inegavelmente, há homofobia na sociedade com consequências nefastas. Mas há também celibatofobia: uma espécie de tabu da antivirgindade, produzido por uma sociedade hipersexualizada. Ambas as fobias são preconceitos, ambas são injustas e intolerantes. A sã cidadania deve reconhecer e estimar os diferentes âmbitos da diversidade humana, e não transformar-se em um preconceito com sinais trocados ${ }^{17}$.

A associação entre pedofilia e homossexualidade, porém, está presente no documento romano de 2005, da Congregação para a Educação Católica, que trata de candidatos ao sacerdócio com tendências homossexuais. A referên-

${ }^{14}$ C. CALLIGARIS, "Pedófilos, celibatários e infalíveis", 1 abr. 2010, e ID., "A fantasia do pedófilo", 25 abr. 2010. Disponíveis em: <http://contardocalligaris.blogspot.com>. Acesso em: 26 jan. 2011.

15 "Marcial Maciel gastava 50.000 euros por dia", Boletim eletrônico IHU, 7 mai. 2010. Disponível em: <www.ihu.unisinos.br>. Acesso em: 26 jan. 2010.

16 "I will not speak at this moment about homosexuality: this is another thing": Interview of the Holy Father Benedict XVI during the Flight to the United States of America, 15 abr. 2008. Disponível em: <www.vatican.va>. Acesso em: 26 jan. 2011. ${ }^{17}$ L.C. LIMA, "Fobias e pedofilia", $O$ Globo, 24 abr. 2010, p. 7. 
cia é indireta: "uma questão particular, que a situação atual tornou mais urgente $^{\prime 18}$. O prefeito desta Congregação, que assina o texto, afirmou em entrevista à imprensa ser inoportuno ordenar tais candidatos, ainda que haja sacerdotes de conduta exemplar com tendências homossexuais ${ }^{19}$.

O assunto em si é algo interno da Igreja, mas este limite inevitavelmente é ultrapassado por implicar uma imagem da pessoa homossexual, o que tem consequências éticas. Alguns louvaram a medida por terem o mesmo entendimento do prefeito. Outros se opuseram, julgando que o Vaticano quer combater os recentes escândalos de abuso sexual punindo os homossexuais. Tais escândalos, argumentam, também têm vítimas meninas e mulheres, e não se questiona a admissão de pessoas heterossexuais ao sacerdócio ${ }^{20}$.

Segundo o documento, compete à Igreja definir os requisitos necessários para a ordenação e chamar os que ela julgar qualificados. No rito latino se supõe o compromisso do celibato; nos ritos orientais, ou o celibato ou um matrimônio (obviamente heterossexual) bem consolidado. O candidato ao sacerdócio deve atingir a maturidade afetiva que o torne capaz de estabelecer uma correta relação com homens e mulheres. E com esta maturidade, desenvolver uma paternidade espiritual em relação à comunidade que lhe será confiada. Cabe ao bispo ou ao superior religioso chamar às ordens, depois de ouvir os encarregados da formação.

Quanto aos homossexuais, diz o texto, deve-se evitar em relação a eles qualquer forma de discriminação injusta. Mas não devem ser admitidos ao seminário e nem ordenados os que "praticam a homossexualidade, apresentam tendências homossexuais profundamente enraizadas ou apoiam a chamada cultura gay" $\left(\mathrm{n}^{\circ} 2\right)$. Estas pessoas se encontram numa situação de grave obstáculo a uma correta relação com homens e mulheres. No caso destas tendências resultarem de um problema transitório, elas devem ser superadas pelo menos três anos antes da ordenação diaconal.

A recepção deste documento, porém, agregou novos elementos. Na tradição eclesial, a recepção é o modo como normas e conteúdos são acolhidos e assimilados na vida das Igrejas locais, e nelas se tornam expressões de fé. As realidades locais e os diferentes horizontes de interpretação têm um papel muito importante neste processo, permitindo compreensões mais matizadas e flexíveis.

O então presidente da Conferência Episcopal Alemã, cardeal Karl Lehmann, afirmou que se deve entender por "tendências homossexuais profundamen-

${ }^{18}$ CONGREGAÇÃO PARA A EDUCAÇÃO CATÓLICA. "Instrução sobre os critérios de discernimento vocacional": Introdução.

19 Z. GROCHOLEWSKI, "Quando não é oportuno admitir ao sacerdócio": Entrevista

a Gianni Cardinale, 30 dias (2005/n.11) 24-26.

${ }^{20}$ J. GRAMICK, "Rompendo o silêncio": Entrevista a Ana Aranha, Época, 12 dez. 2005.

Disponível em: <http://revistaepoca.globo.com>. Acesso em: 26 jan. 2011. 
te enraizadas", não quaisquer tendências neste sentido, mas aquelas que são um grave obstáculo para uma correta relação com homens e mulheres ${ }^{21}$. Seguindo esta interpretação, também as tendências heterossexuais profundamente enraizadas são um grave obstáculo.

O ex-superior geral dos dominicanos, Timothy Radcliffe, trabalhou em todo o mundo com bispos e padres, diocesanos e religiosos. Ele afirmou não ter dúvidas de que Deus chama homossexuais ao sacerdócio. E afirma que eles estão entre os sacerdotes mais dedicados e impressionantes que encontrou. Por isso nenhum sacerdote que esteja convencido de sua vocação deve se sentir classificado pelo documento como incapaz. E pode-se presumir que Deus continuará chamando ao sacerdócio tanto homossexuais como heterossexuais, porque necessita dos dons de ambos.

Quanto à "cultura gay", Radcliffe diz que seminaristas e sacerdotes não devem frequentar bares gays e que seminaristas não devem desenvolver uma subcultura gay. Qualquer subcultura sexual, gay ou hétero, é incompatível com o celibato. Mas apoiar a "cultura gay" significa apenas isto? Interroga ele. O documento afirma que a Igreja deve se opor à discriminação injusta contra os homossexuais, assim como ela se opõe à discriminação racial. Isto significa, então, que todos os sacerdotes devem estar preparados para se colocarem ao lado dos gays caso eles sofram opressão. E serem vistos do lado deles.

A sociedade, diz ele, tem obsessão por sexo, e a Igreja deveria oferecer um modelo de sã e não compulsiva aceitação da sexualidade. O Catecismo do Concílio de Trento ensina que o sacerdote deve tratar de sexo "de preferência com moderação do que com excesso". Deveria haver mais atenção a quem os seminaristas podem odiar do que a quem eles amam. Racismo, misoginia e homofobia deveriam indicar que alguém pode não ser modelo de Cristo ${ }^{22}$.

A Conferência dos Bispos Suíços também se pronunciou sobre a admissão ao sacerdócio:

Nós somos profundamente gratos a todos os padres que vivem sua vocação com grande fidelidade. Nós temos consciência de que em nosso colégio presbiteral e nos nossos seminários vivem co-irmãos com orientação heterossexual e outros com orientação homossexual. Nós respeitamos cada um como homem e co-irmão. Nós decidimos viver a castidade independentemente de nossa orientação sexual. Por isso, no âmago de nossas reflexões sobre o acesso ao sacerdócio, não há questão de orientação sexual, mas a disponibilidade de seguir Cristo de maneira coerente ${ }^{23}$.

\footnotetext{
${ }^{21}$ K. LEHMANN, "Le service presbytéral requiert l'homme tout entier", $L a$ documentation catholique 103 (2006/n.2349) 36-37, aqui p. 36.

${ }^{22}$ T. RADCLIFFE, "Can gays be priests?", The Tablet, 26 nov. 2005. Disponível em: <http://www.thetablet.co.uk/article/662>. Acesso em: 27 jan. 2011.

23 CONFÉRENCE DES ÉVÊQUES SUISSES, Déclaration "La chasteté, indépendamment de l'orientation sexuelle”, La documentation catholique 103 (2006/ n.2349) 33-34, aqui p. 33.
} 
Como se pode notar, a recepção do documento romano estimulou uma fidelidade criativa em alguns segmentos da Igreja. A reflexão se aprofundou, os conceitos foram matizados e se abriram caminhos, com um apreço maior pela pessoa homossexual.

Em 2008, a mesma Congregação lançou um novo documento: sobre o uso da psicologia na admissão e na formação de candidatos ao sacerdócio ${ }^{24}$. A formação para o sacerdócio é compreendida como uma configuração a Cristo, bom pastor. Nesta formação, deseja-se cultivar motivações espirituais e buscar um equilíbrio humano e afetivo, para que haja liberdade interior na relação com os fiéis, em uma vida celibatária. O uso da psicologia através de testes e de psicoterapia é recomendado em certas circunstâncias, mas não é obrigatório.

O caminho formativo deverá ser interrompido, determina a Congregação, no caso de o candidato, apesar do seu empenho e do apoio psicológico, ser incapaz de "enfrentar de modo realista" suas graves imaturidades. Entre elas são mencionadas: forte dependência afetiva, notável falta de liberdade nas relações, excessiva rigidez de caráter, falta de lealdade, identidade sexual incerta e tendências homossexuais fortemente enraizadas. $\mathrm{O}$ mesmo vale no caso de excessiva dificuldade com o celibato, "vivido como uma obrigação tão penosa a ponto de comprometer o equilíbrio afetivo e relacional" ${ }^{\prime 25}$.

Note-se que a orientação homossexual, ainda que classificada como grave imaturidade, não é a causa de afastamento, mas a incapacidade de se lidar com ela de maneira adequada. A restrição do documento anterior foi amenizada. E, seja quem for o candidato, não deve viver o celibato a qualquer preço, sacrificando o seu equilíbrio emocional. Esta sábia norma é muito oportuna também para a vida religiosa e para os fiéis leigos.

Em meio a toda esta polêmica, a autoestima de seminaristas ou sacerdotes homossexuais é bastante bombardeada. É preciso que haja um ambiente de confiança onde eles possam admitir a sua condição, ainda que apenas para si mesmos, para seus orientadores espirituais e para seus superiores. E que possam conversar, refletir e orar sobre isto. Caso contrário, a homossexualidade enrustida terá efeitos devastadores em si mesmos e nos outros. Faltam modelos explícitos de santidade homossexual, nos quais as pessoas possam se inspirar.

${ }^{24}$ CONGREGAÇÃO PARA A EDUCAÇÃO CATÓLICA, "Orientações para a utilização das competências psicológicas na admissão e na formação dos candidatos ao sacerdócio", Roma, 2008. Disponível em: <www.vatican.va>. Acesso em: 27 jan. 2011.

${ }^{25}$ Ibid., $\mathrm{n}^{\mathrm{o}} 10$. 
A desconfiança e a suspeita ainda pairam sobre os gays. Os bispos suíços categoricamente se distanciaram delas. Os bispos brasileiros, porém, ao alertarem contra candidatos homossexuais ao sacerdócio como uma medida para se enfrentar os abusos sexuais do clero, acabam mantendo a associação entre homossexualidade e pedofilia.

Até o presente, tudo parece indicar que o clero não é mais pedófilo do que outros segmentos da sociedade. Os homossexuais também não. É preciso superar suspeitas e desconfianças indevidas, bem como hostilidades recíprocas. Para a Igreja Católica, restam ainda os seguintes desafios: de romper a endogenia eclesiástica, onde se quer resolver tudo apenas no âmbito interno, excluindo as instâncias civis; de afastar-se do clericalismo, que exalta demais a figura do sacerdote em detrimento do laicato e do seu necessário protagonismo; de superar o moralismo, sobretudo no campo sexual, para que o Evangelho, anúncio alegre do reinado de Deus, predomine sobre as proibições.

Com as normas eclesiásticas atuais, já se pode romper a endogenia. Com a evolução doutrinária a partir do Concílio Vaticano II, já é possível valorizar o laicato e redimensionar a figura do sacerdote. Mas a mudança leva tempo, pois a cultura eclesial tem sua inércia.

Quanto ao moralismo, certa vez o papa Bento XVI declarou que o cristianismo "não é um conjunto de proibições, mas uma opção positiva". E acrescentou: "É muito importante que evidenciemos isso novamente, porque essa consciência, hoje, desapareceu quase que completamente" ${ }^{\prime 26}$. Um papa reconhecer isto é muito bom e oportuno. Cabe perguntar: o que fez o cristianismo ser visto hoje como um conjunto de proibições? Por que a consciência de que ele é uma opção positiva quase desapareceu?

Há na tradição cristã um forte componente multissecular de insistência na proibição, no pecado, na culpa, na condenação e no medo. O historiador francês Jean Delumeau fala de uma "pastoral do medo", ou seja, o recurso constante à ameaça de condenação eterna para se obter a conversão ${ }^{27}$. Mas não só no passado distante. Também no presente, muitos interpretam a doutrina maximizando restrições e condenações, com fixação no pecado, sobretudo ligado a sexo. Para isso, usam insistentemente o púlpito e a mídia, e veem por toda parte demônios e inimigos de Cristo, ativos e atentos. O resultado é o desnecessário tormento de muitas consciências, bem como o descrédito e o afastamento de tantas pessoas lúcidas. Gasta-se uma enorme energia inutilmente, perdendo-se o foco de muitas coisas importantes e tantas chances de se fazer o bem.

\footnotetext{
26 "Entrevista de Bento XVI em previsão de sua viagem à Baviera (1)", Agência Zenit, 16 ago. 2006. Disponível em: <http://www.zenit.org>. Acesso em: 31 ago. 2006.

${ }^{27}$ J. DELUMEAU, $O$ pecado e o medo: a culpabilização no ocidente (séculos 13-18), Bauru: EDUSC, 2003, 2 vols.
} 
O discurso moral carregado demais, como foi observado, também faz voltar a atenção sobre as transgressões do clero, dando-lhes uma importância desproporcional. O cristianismo precisa trilhar um caminho novo, o da opção positiva e do alegre anúncio dos dons de Deus.

Para além do moralismo, é necessário reconhecer, deve haver uma justa preocupação com os outros abusos sexuais, não cometidos pelo clero. Há no mundo um mercado de pornografia e um turismo sexual que envolve crianças e adolescentes pobres, causando-lhes forte devastação psicológica. Recentemente o papa revelou o que tem escutado sobre isto de bispos de países do Terceiro Mundo: o quanto o turismo sexual traz de dano a toda uma geração ${ }^{28}$. É mais uma face perversa da exploração econômica.

Para finalizar, há esperança de que a percepção lúcida do problema seja o início da mudança. Segundo Radcliffe, "estamos vivendo a crise de toda aquela concepção do sacerdócio, com o seu distanciamento das pessoas, o seu uso do poder, a sua concepção da moral como controle". Esta crise é também uma chance de amadurecimento, abandonando as seguranças do tempo da cristandade, e de uma Igreja então concebida como sociedade perfeita e autossuficiente. Com o nosso grande sofrimento, prossegue o exsuperior geral dos dominicanos, "o Senhor está destruindo as nossas altas torres e as nossas expectativas de glória e de grandeza, para estabelecer morada junto de nós"29.

Luís Corrêa Lima SJ é professor do Departamento de Teologia da PUC-Rio, e membro do seu programa de pós-graduação. Graduou-se em filosofia e em teologia na FAJE, em Belo Horizonte, e fez doutorado em história na UnB, em Brasília. É autor dos livros Teologia de Mercado: uma visão da economia mundial no tempo em que os economistas eram teólogos, Bauru: Edusc, 2001, e Fernand Braudel e o Brasil: vivência e brasilianismo, São Paulo: Edusp, 2009. Desenvolve pesquisa sobre história da Igreja, modernidade e diversidade sexual.

Endereço: Rua Marquês de São Vicente, 389 22451-041 Rio de Janeiro - RJ e-mail: lclima@puc-rio.br

28 "Discurso do papa Bento XVI por ocasião da troca de votos natalícios com a cúria romana", 20 dez. 2010. Disponível em: <www.vatican.va>. Acesso em: 17 fev. 2011. 29 "A crise da Igreja. Artigo de Timothy Radcliffe", Boletim eletrônico IHU, 13 mai. 2010. Disponível em: <www.ihu.unisinos.br>. Acesso em: 28 jan. 2011. 